\title{
La función de la mirada clínica en el tratamiento de niños con quemaduras
}

\author{
Xochiquetzaly Yeruti de Ávila Ramírez, ${ }^{1}$ Manoel Tosta Berlinck²
}

Artículo original

\section{SUMMARY}

The subject of this paper focuses on the clinical role of the gaze. The study, based on clinical and theoretical postulates of fundamental psychopathology, discusses mental suffering caused by the destruction of skin. We analyze elements for the clinical management of children hospitalized for burns in order to show the importance of a (visual) device that functions as: 1. a suture for the invasive opening that physical and psychological injuries generated due to the violent and unexpected destruction of skin, 2. protection and symbolic restitution of tissues related to resignifications of mental suffering in a body with burns.

Key words: Clinical gaze, fundamental psychopathology, burns, mental suffering.

\section{RESUMEN}

El tema del presente trabajo se centra en la función clínica de la mirada. Partiendo de los postulados clínico-teóricos de la Psicopatología Fundamental, el pathos psíquico impuesto por la destrucción de piel constituye el eje de nuestro análisis. Proponemos observar algunos elementos del tratamiento clínico a niños hospitalizados por quemaduras para mostrar la importancia de un dispositivo (visual) que funcione como: 1 . sutura sobre la abertura desestructurante que ataques físicos y psíquicas generan debido a la violenta y sorpresiva destrucción de piel, 2. abrigo y restitución de tejidos simbólicos que invistan las resignificaciones de pathos en un cuerpo con quemaduras.

Palabras clave: Mirada clínica, Psicopatología Fundamental, quemaduras, pathos.

\section{INTRODUCCIÓN}

El efecto de lo psíquico en el cuerpo adquirió desde hace mucho tiempo consideraciones relevantes en el campo del saber médico. Se constata la existencia de una relación mutuamente incluyente entre observación y tratamiento dirigidos, respectivamente, a los elementos objetivos y subjetivos del cuerpo. Ante esta dupla visibilidad del cuerpo, el contenido del presente trabajo busca reflexionar acerca del pathos psíquico que se manifiesta en niños con quemaduras durante el proceso de hospitalización.

Se enfatiza el estatuto fundamental (y fundante) de la mirada clínica y sus efectos sobre el proceso en que el cuerpo es atacado por quemaduras que provocan dolor, sufrimiento y transformaciones que revelan dimensiones específicas de algún tipo de psicopatología.

Lo anterior surge a partir de un caso clínico que permite analizar dos elementos centrales en el tratamiento de pacientes con quemaduras: la función clínica de la mirada y la dilucidación de dimensiones psicopatológicas que se presentan durante la vivencia de quemaduras, responsables de producir una abertura físico-psíquica en niños.
La estructura del trabajo se propone en tres fases: primero con la presentación del caso clínico, posteriormente la formalización teórica y finalmente un análisis de algunas de las dimensiones psicopatológicas observadas durante el tratamiento clínico.

\section{PRESENTACIÓN DEL CASO CLÍNICO}

A sus cinco años de edad, Fernando es internado en el hospital debido a quemaduras de segundo grado provocadas con gasolina en 35\% de la superficie corporal total (SCT). Jugando con primos y amigos alrededor de una fogata, accidentalmente cae gasolina sobre Fernando, quien instantáneamente se ve envuelto en fuego. Ante el ardor y pánico, comienza a correr sin dirección y gritar pidiendo auxilio. Al ser avisado, su papá corrió hasta él, lo tiró al piso y comenzaron a rodar juntos en un intento por detener el fuego que se esparcía velozmente lastimando el cuerpo de Fernando. Después de apagar el fuego, rápidamente cubren a Fernando con una manta para trasladarlo al hospital donde recibió atención en urgencias pediátricas $\mathrm{y}$, posteriormente, proporcionarle cuidados especializados.

\footnotetext{
Laboratório de Psicopatologia Fundamental. Programa de Pós-graduação em Psicologia Clínica, Pontifícia Universidade Católica de São Paulo, PUC-SP. Brasil. 2 Associação Universitária de Pesquisa em Psicopatologia Fundamental, AUPPF. Laboratório de Psicopatologia Fundamental. Programa de Pós-graduação em Psicologia Clínica, Pontifícia Universidade Católica de São Paulo, PUC-SP. Brasil.

Correspondencia: Xochiquetzaly Yeruti de Avila Ramírez. Rua Tupi 397, Ci. 104. CEP 01233-001 São Paulo, SP/Brasil. E-mail: xo_yeruti@yahoo.com.mx

Recibido: 14 de febrero de 2012. Aceptado: 13 de agosto de 2012.
} 
Durante una de las visitas al área donde Fernando fue internado, su papá se aproximó para solicitar apoyo psicológico para su hijo. Las razones que refirió fueron llanto intenso y constante así como insomnio y pesadillas, además de resaltar que Fernando estaba muy asustado por la presencia de "alguien" que se lo quería llevar, pues con frecuencia, Fernando aseguraba que "un hombre muy feo" aparecía en su cuarto.

Al comienzo de la hospitalización, durante las primeras curaciones, aseos quirúrgicos e intervenciones médicas, Fernando se mostró angustiado e inquieto ante la incertidumbre y el horror de no reconocer el contorno o límite entre su cuerpo y el exterior. Fernando mantenía prolongados periodos de llanto y agitación, al tiempo de suplicar con efusivos gritos "déjenme, por favor déjenme", además de rechazar irritadamente cualquier acercamiento o contacto del personal médico. Tales aproximaciones eran traducidas como amenazas de invasión a través del frágil contorno de su cuerpo.

Más allá del dolor, el llanto y los gritos se debían a la amenaza que el acercamiento de otros producía (hiperestesia), excitando la abertura corporal a través de la cual Fernando no lograba distinguir si algo de su cuerpo se fugaba o si, por el contrario, algo ajeno y desconocido lo invadía.

El llanto intenso y anticipado ante la inminencia del contacto se relacionaba con el pathos de una abertura en la que los límites corporales quedan disueltos, la sensorialidad aumentada y las defensas y protecciones psíquicas debilitadas. El llanto brotaba, ante la herida perpetuada por lo ajeno, como hemorragia psíquica en la abertura provocada por la ausencia real y simbólica de un tejido protector y resistente que, al mismo tiempo, detuviera la fuga de lo propio.

El primer encuentro con Fernando aconteció durante una mañana de los primeros días de su internamiento, dentro del área de atención médica especializada. Saludé, me presenté y desde la puerta le solicité permiso para entrar y acercarme a él.

Con lágrimas en los ojos, Fernando giró la cabeza en dirección a su papá y procuró una confirmación (pues ya había sido avisado de mi visita). Fernando accedió y así comenzamos nuestros encuentros y tratamiento clínico, a partir de un dispositivo visual, ${ }^{*}$ es decir, un tejido de miradas: tres miradas (la del propio paciente, la mirada paterna y la mirada del clínico) comenzaban un trabajo de sutura simbólica sobre los bordes del cuerpo que fueron dañados.

Durante uno de los encuentros clínicos posteriores, Fernando pronunció: "Dios me castigó por ser malo y desobedien$t e^{\prime \prime}$, frase que con esas u otras palabras, fue frecuentemente repetida, así como otra expresión que también denotaba un sentimiento de culpa: "diosito, diosito, por favor perdóname".

De esta forma, el llanto que Fernando presentó durante los primeros días de su hospitalización se convirtió en "fuga de palabra", intentos de apalabrar y dar sentido a la vivencia y subjetivar el dolor. Los gritos y la irritación disminuyeron, dando lugar a un discurso que develó profundo sentimiento de culpa, en el que Fernando pasó de la hiperestesia a la analgesia: la culpa intensa menguó las sensaciones de dolor.

Después de algunas curaciones, los médicos que cuidaron de Fernando programaron la primera cirugía de toma y aplicación de injertos (TAI). Fernando preguntó si estaría presente en su cirugía, respondí con una negativa, por lo que pidió que estuviera con él mientras la cirugía fuera realizada.

Siguiendo rigurosos procedimientos y respetando cuidadosos protocolos los médicos autorizaron mi solicitud en respuesta al pedido de Fernando. Poco antes de su traslado, Fernando preguntó: ¿me vas a ver allá?, -sí, allá nos veremos, respondí. Cerramos un pacto, un encuentro de y con la mirada que reforzaba el dispositivo visual que estábamos construyendo. Dentro del quirófano, Fernando dijo -voy a cerrar los ojos y dormir, pero tú ves todo lo que ellos me hacen y después me cuentas.

Durante el traslado y los preparativos para la cirugía, Fernando se mostró tranquilo, cada uno de los médicos que lo cuidaban (pediatra, cirujano y anestesiólogo) le había explicado detalladamente el proceso quirúrgico que sería realizado. Explicaciones sencillas que cumplieron la función de contener la angustia ante lo inquietante, lo que podemos interpretar como "lo ominoso": Das Unheimlich. ${ }^{1}$

La cirugía se llevó a cabo y después de un periodo post-quirúrgico de recuperación, Fernando nuevamente fue trasladado al cuarto del área de quemados donde su papá lo esperaba.

En el momento en que las enfermeras recibieron a Fernando y cuidadosamente buscaron la forma de procurarle comodidad, le retiraron la sábana que cubría su cuerpo mientras su papá observaba la imagen desde afuera. Al verlo con vendas cubriendo los injertos y gasas deteniendo la hemorragia del área donadora, la imagen es para el padre de dimensiones tan siniestras que no consigue contener el llanto y se retira prohibiendo la mirada, al tiempo en que Fernando esperaba su aproximación.

La desviación de la mirada del padre produjo una interrupción en la que Fernando dejó de ser sostenido y quedando abandonado ante el terror de lo indescifrable de una imagen de sí que atemorizó a su padre y, a él, lo colocó en la vulnerabilidad y el desamparo.

Después de dirigir para Fernando una mirada por medio de la cual intenté decirle "espera", con la intención de asegurar una unión, salí buscando a su papá, pero la triangulación de miradas que se tejía como soporte para Fernando ya había sufrido una ruptura.

Castigado por ser malo y rechazado por una indescifrable, indecible imagen de sí, Fernando mira desesperadamente su cuerpo y asustado comenzó a gritar y llorar quejándose de dolor y frío intensos.

En los siguientes días Fernando casi no se movió, mantuvo una posición estática (poco común tratándose de ni-

* Designamos lo "visual" como una forma de destacar la importancia de la mirada en el tratamiento clínico de niños con quemaduras. 
ños), una posición de petrificación. El desvío de la mirada de su papá provocó un vacío, una fractura en la consecución de las funciones psíquicas que buscaban suturar simbólicamente las heridas, representar la vivencia de dolor y propiciar una reparación narcisista.

\section{DISCUSIÓN}

Escribir al respecto de lo real del cuerpo implica un trabajo de observación: presencia soporte y mirada acompañante en los encuentros con lo siniestro. La importancia clínica de la mirada versa sobre elementos que contienen, en su forma y desenvolvimiento, la visibilidad del cuerpo, de lo que crea y modela una figura: expresión de lo que se manifiesta de nuevo y de lo que se transforma, ${ }^{2}$ es decir, de lo fundante y constitutivo de la imagen inconsciente del cuerpo. ${ }^{3}$

Así, la observación y, más específicamente, la mirada, adquieren un estatuto central en la clínica de niños con quemaduras. Observación y mirada son el comienzo y la vía para generar encuentros, reflejos y transferencias en el tratamiento de las quemaduras, un diálogo transformador ante lo siniestro del pathos psíquico en el cuerpo.

Cuando fuerzas antagonistas se encuentran justamente en el cuerpo y, cuando tal oposición deriva en sufrimiento, rupturas y desligamientos, se traza y abre una lesión físico-psíquica. Por lo tanto, el trabajo clínico dirigido a niños con quemaduras remite a aquello que acontece súbitamente violentando los límites e instalándose como una afectación de diversas y desconocidas consecuencias.

El cuerpo desconocido y lo desconocido del cuerpo se revelan parcialmente en la singularidad de trazos inscritos por el discurso que brota de y en él. Así, el discurso del cuerpo es un texto que puede leerse, pues se revela a la mirada del otro como escenario de diálogos con lo inesperado, asombroso y sorpresivo.

El pathos brota en el cuerpo y hace de él un espacio expuesto a la mirada que opera como membrana invisible y protectora, capa erótica que cubre al cuerpo, extendiéndose como textura de relacionamientos inter y transcorporales.

Esa superficie se constituye como un campo de discurso donde el silencio también delinea un texto en el Yo. Tal dimensión silenciosa es atendida por los efectos clínicos de la mirada al operar como soporte de los discursos del cuerpo, sus marcas y ordenamientos.

Ya que la piel se constituye como una superficie de percepción, ${ }^{4}$ es decir, de datos e inscripciones sensoriales, la intención de la observación y la mirada, en la clínica de niños con quemaduras, es bordear (o bordar) tales fenómenos y propiciar encuentros que lleven a la reconstrucción de un sentido y resignificación de aquello que, al dañar el cuerpo, perturbó al psiquismo.

Observar es inclinarse hacia lo desconocido, adentrarse más allá de lo manifiesto y, en la clínica de niños con quema- duras, intentar ubicar la irregularidad que daña y perturba, en un lugar donde pueda abrirse a la reflexión y al pensamiento.

En el tratamiento clínico, mientras la escucha intenta propagarse para introducir una interpretación sobre el sentido oculto de las palabras, la mirada busca inclinarse sobre lo desconocido del cuerpo para develar algo que engendre la transformación del trauma en experiencia. ${ }^{5}$

Tal transformación puede gestarse por la vía clínica de la mirada que lleve en cuenta la complejidad de la biología, de la lógica de la vida ${ }^{6}$ como sistema natural, es decir, campo de afectos, sutilezas, complicaciones y pasiones.

De la misma forma en que los vendajes se adhieren como borde que controla la hemorragia y protegen las heridas, la mirada del clínico cumple una función homóloga en el psiquismo: traza las líneas que se organizan como membrana (recubrimiento) simbólico del cuerpo, cuyo efecto constituyente es unir y proteger.

Hay en la mirada una acción refleja de soporte psíquico frente a lo real. ${ }^{7}$ En el silencio que lo real impone, en la ausencia de palabras que pronuncien un sentido, la mirada clínica sobre el cuerpo produce un efecto inaudible pero sólido, de contención, unión y soporte. La existencia se sostiene en la mirada del otro, si ésta falta (o falla), los bordes, componentes y formas del cuerpo se disuelven y las funciones del Yo se debilitan.

Cuando el pathos rebasa violentamente la comprensión, como en el caso clínico presentado, se puede observar que más allá del dolor, no ser amado o ser rechazado agrede el narcisismo, violenta el cuerpo y actúa contra el psiquismo, generando desamparo y vulnerabilidad.

En el tratamiento de niños hospitalizados por quemaduras, se plantea como componente fundamental el estatuto de la función clínica de la mirada, pues desde etapas tempranas de la vida la mirada del otro recubre e inviste, teje en cada uno una membrana que en adelante será recubrimiento bajo el cual nos presentaremos (o defenderemos) ante el ambiente y los otros.

La mirada es un (con) tacto, una vía de aproximación que puede desplegarse como un acercamiento constituyente. Pensamos la mirada como una cualidad de la observación clínica para subjetivar, figurar y sostener, pues la mirada se teje como vestido psíquico y membrana del cuerpo: textura corporal transubjetiva.

Para cumplir las funciones constitutiva y configurativa de la mirada, el clínico debe trabajar como un bricoleur, crear lazos hasta formar ligaciones que regeneren una membrana narcisistamente protectora.

Mirar suscita ligaciones que organizan el cuerpo y sus inscripciones de y al deseo. Es así como por medio de la mirada se puede reflejar el Eros pero, también, la destructividad. Mientras la destructividad está ligada al desamparo y vulnerabilidad ante la rememoración de las pérdidas que se fugan por una abertura psíquica, el deseo envuelve al narcisismo que da cuenta del erotismo constitutivo. 
Así mismo la mirada puede regenerar y destruir, puede propagarse: a) sobre el lugar de la abertura psíquica, señalando la destrucción de las quemaduras e intensificando los efectos del pathos o, b) sobre el lugar de Eros, tejiendo una membrana erótico-narcisista cuya sutura instituye una condición que cubre, sana y hace lazo al deseo.

La mirada del clínico debe extenderse como invitación dirigida al paciente para mirarse, protegerse, regenerar los tejidos de su membrana simbólica y erotizar su cuerpo, es decir, crear una transferencia de representación soporte.

El conflicto psíquico provocado por quemaduras es de tales dimensiones que exige un cuidado exhaustivo, trabajo de ordenamiento que no se alcanza sólo en la escucha del dolor. En la clínica de pacientes con quemaduras no es suficiente dar lugar a la palabra o la interpretación, es también, a través de la mirada, que una tentativa de ordenamiento psíquico puede acontecer.

Hasta aquí intentamos aproximarnos a la función de la mirada del clínico, pero ¿qué acontece con la mirada del paciente al mirarse a sí mismo?, ¿qué es lo que opera en ese reflejo de sí? en las próximas líneas intentaremos abordar brevemente las implicaciones de la mirada del paciente.

Se intentará diferenciar los efectos de la destrucción de la piel, a partir de los cuales los elementos psíquicos revelan formas de funcionamiento ligadas a dimensiones psicopatológicas.

Por medio del trabajo de observación clínica en niños con quemaduras podemos inferir las dimensiones de excepcionalidad, culpa y melancolía, ${ }^{8}$ como formas de respuesta delante del acontecimiento de devastación producido por las quemaduras, sus consiguientes pérdidas y desligamientos. Una configuración específica de la mirada, en su singularidad, revela el lugar que el paciente ocupa frente a la destrucción, oblación o pérdida del Yo.

La excepcionalidad ante la destrucción. Mirada sádica. Sobre los excepcionales, Freud" afirma: "Todos nosotros pensamos que tenemos motivo para reprender a la Naturaleza y nuestro destino por desventajas congénitas e infantiles; todos exigimos reparación por antiguas heridas a nuestro narcisismo, a nuestro amor propio". En niños con quemaduras, éstas se configuran como una herida narcisista haciendo que el $p a-$ thos y las sensaciones de dolor sean interpretadas como una autorización para agredir, violentar y hasta herir a los otros.

Los niños que presentan esta dimensión de excepcionalidad resuelven actuar como villanos con la excusa de un pasado en el que fueron injustamente perjudicados. Bajo tal excusa la forma de mirarse y mirar a los otros adquiere una cualidad sádica, pues hay una expresión de odio en el marco de una mirada de dominio, fija, agresiva y profunda.

Para los excepcionales parece no haber posibilidad de renuncia a la satisfacción, exigen placer porque en las quemaduras recibieron imposiciones destructivas de dolor y violentas transformaciones en su imagen y su cuerpo. Tales efectos configuran posteriormente la condición de excep- cionalidad, es decir, deben recibir con prontitud la satisfacción de un placer. Exigen la reparación total de su pérdida y dolor. El excepcional se inscribe en una posición sádica a través de la cual intenta redimir el violento e injusto ataque perpetrado por las quemaduras.

Podemos resaltar que en la excepcionalidad se encuentra presente la certeza de que un mal les fue injustamente impuesto lo que autoriza dominio sobre los otros a través de rabiosas expresiones en su mirada, al manifestar una exigencia irrestricta de placer, además de determinación para destruir y agredir.

El sacrificio y la oblación de la piel. La mirada del Super Yo. Mientras los excepcionales se asumen sin culpa, otros muestran un conflicto fuertemente ligado a la idea de un castigo merecido e impuesto por consecuencia de una falta grave cometida en el pasado. Prevalece la idea de haber fallado o incumplido en algo, lo que se vuelve intolerable, y pensamientos incansables de expiación y castigo. En los niños que muestran sentimiento de culpa, la angustia, el dolor y el pánico son el merecido castigo que reciben por la falta inconsciente cometida en etapas tempranas de la vida.

En torno de la noción de castigo podemos resaltar que desde la antigüedad, la pena impuesta a los responsables de crímenes o pecados está asociada con quemaduras. Recordemos que desde un punto de vista religioso, concretamente cristiano, aquello que es impuro se purifica por medio del fuego. Según ciertos pasajes bíblicos, el fuego del sacrificio es la divinidad que devora a la víctima. ${ }^{10}$

Bíblicamente se adjudica al sacrificio un ritual en que toda impureza o maldad es extinta o purificada con fuego, calor intenso o llamas. Recordemos también que, para recibir la gracia divina, el hombre debe desprenderse de todo placer carnal, padecer y negarse a la satisfacción.

Podemos pensar que en las quemaduras la piel se ofrece como oblación. El sacrificio es la propia piel, la membrana del cuerpo que traza el límite entre lo propio y extraño. Tal membrana se ofrece como oblación para su destrucción y cese de sensaciones placenteras. Tal destrucción es llamada de sacrificio.

Se debe llamar sacrificio a toda oblación en que la ofrenda, o una parte de ella, es destruida. También se resalta que el sacrificio sirve a dos finalidades: para adquirir un estado de santidad o para suprimir el estado de pecado. ${ }^{10}$

De esta forma se puede pensar que la destrucción de la piel, inherente a las quemaduras, se establece como sacrificio expiatorio que libere la culpa provocada por la idea inconsciente de un mal, falta o pecado cometido.

Es común observar que niños con quemaduras que manifiestan culpabilidad atraviesan el proceso de hospitalización bajo niveles de mayor tolerancia al dolor. En quienes se instala la dimensión de culpabilidad, el intenso dolor en el cuerpo se asume como intento de reparación y/o búsqueda del perdón (divino - paterno-). 
El pecado está en el cuerpo y pertenece al orden del deseo edípico. Tal pecado es opresivo y se convierte en culpa que no se atenúa, a no ser por una punición que opere como límite, y de esa forma la deuda es saldada. En la dimensión de culpa la deuda es con el Super Yo y, el pago son la piel y el dolor, de esa forma, la absolución es alcanzada.

Los niños que presentan sentimiento de culpa son dominados por el terror de estar en pecado y ser por consiguiente, indignos de la gracia de Dios. Destacamos que estar bajo la Gracia Divina remite a estar bajo el agrado del padre. Así, en quienes domina la culpa, la mirada expresa sumisión, devoción y lamento expiatorio.

Melancolía y depreciación por la pérdida de piel. Mirada omnipresente. En algunos niños con quemaduras, la intensa depreciación en ellos observada sugiere ocuparnos de la melancolía como otra forma de respuesta que se revela en el difícil proceso de hospitalización.

Es difícil descifrar lo que en la piel se lleva, por lo tanto también resulta complejo dimensionar lo que en las quemaduras se pierde, porque más allá de las heridas físicas, se traza una abertura psíquica que coloca al paciente ante la imposibilidad de subjetivar lo perdido y de reconocer sus dimensiones. Imposibilidad de reparar el orden violado e investir de significado el acontecimiento que impuso marcas en el Yo.

En la respuesta melancólica ante las quemaduras, el paciente queda anclado en la abertura, es decir, la mirada se fija omnipresente sobre el indescifrable vacío. Dicha fijación revela la falta en que la pérdida no es en el Yo, sino de él, es decir, es el Yo lo que se configura como pérdida. Las quemaduras provocan una abertura en el Yo que señala una fuga y vacío de dimensiones inestimables. Por tal, en ese reflejo la mirada se trasluce vacía, lejana y ausente, fuera y distante al campo de uniones.

El trabajo de duelo por la pérdida de la propia piel fracasa y debilita el narcisismo del paciente. Debilidad narcisista producida por depreciaciones que trazan vacío y decepción ante la impotencia del cuerpo al ataque violento de las quemaduras. El paciente sucumbe a una profunda decepción de sí y de su cuerpo.

Freud $^{11}$ afirma que la dimensión melancólica resalta el desagrado moral para con el Yo y que las auto-recriminaciones son dirigidas a un objeto amado. En el caso de las quemaduras, sus efectos rompen la envoltura narcisista que protege al aparato psíquico amenazando la constancia estructurante del cuerpo.

Hablar de la dimensión melancólica en las quemaduras es referirse a la pérdida del Yo que hace desaparecer la membrana narcisista. La mirada se distribuye omnipresen- te sobre la vulnerabilidad y falla del cuerpo. La insistente depreciación del propio cuerpo y la imposibilidad de subjetivar la pérdida, aniquilan los intentos del Yo por conservarse. Entonces, la mirada se fija irrestrictamente sobre la pérdida del Yo, abertura psíquica y falla física: elementos de una omnipresencia melancólica.

Después del análisis del caso clínico presentado y de la incursión teórica realizada, concluimos que en el tratamiento de niños con quemaduras debe incluirse un dispositivo visual, es decir, dar espacio y vía a una mirada clínica que posibilite funciones de sutura y contención sobre la abertura somato-psíquica: turbulencias subjetivas desestructurantes que colapsan y paralizan la historización entre elementos que permiten la resignificación de la experiencia. Esta tarea tiene precedencia en la creación de ligaciones, en la articulación sólida de lazos vitales del cuerpo.

La mirada como dispositivo visual en el tratamiento clínico es una forma restauradora de abrigo y protección. Tal restauración de la textura corporal será siempre incompleta, tendrá siempre puntos ciegos, huecos en la abertura. Digamos que en tanto sutura simbólica sobre la abertura producida por las quemaduras, nunca la cubrirá por completo; sin embargo, esa insuficiencia también deberá trazarse como invitación al movimiento, convocación para salir de la pasividad, para transitar del derrumbamiento a la búsqueda activa, creativa y expresiva de Eros.

\section{REFERENCIAS}

1. Freud S. Lo ominoso. En: Strachey J (ed.). Sigmund Freud: Obras completas. Segunda edición. Buenos Aires: Amorrortu; 1919/1986; pp. 215-251.

2. Aurerbach E. Figura. Madrid: Trotta; $1998 . \quad 3 . \quad$ Dolto F. La imagen inconsciente del cuerpo. Buenos Aires: Paidós; 1986.

4. Anzieu D. El yo-piel. Quinta edición. Madrid: Biblioteca Nueva; 2007.

5. Berlinck M. Psicopatologia fundamental. São Paulo: Escuta; 2008.

6. François J. La lógica de la vida: uma história da hereditariedade. Rio de Janeiro: Edições Graal; 1983.

7. Lacan J. El estadio del espejo como formador de la función del yo [je] tal como se nos revela en la experiencia psicoanalítica. En: Lacan J. Escritos. Vigesimocuarta edición. Vol. 1. México: Siglo XXI; 1949/2003; pp. 86-93.

8. Ramírez X. Duelo por la piel. Análisis del acompañamiento terapéutico como dispositivo psicoanalítico de intervención a niños hospitalizados por quemaduras. Tesis de Maestría para obtener el grado de Maestra en Psicología. Facultad de Psicología de San Luis Potosí, Universidad Autónoma de San Luis Potosí, San Luis Potosí, México; 2009.

9. Freud S. Algunos tipos de carácter dilucidados por el trabajo psicoanalítico. En: Strachey J (ed.). Sigmund Freud: Obras completas. Segunda edición. Vol. 14. Buenos Aires: Amorrortu; 1916.

10. Maus M, Hubert H. Sobre o sacrifício. São Paulo: Cosac Naify; 2005.

11. Freud S. Duelo y melancolía. En: Strachey J. (ed.). Sigmund Freud: Obras completas. Segunda edición. Vol. 14. Buenos Aires: Amorrortu; 1917[1915]/1984; pp. 235-255.

Artículo sin conflicto de intereses 